\title{
Dynamic Effects of MERCOSUR: An Assessment for Argentina
}

\author{
Germán Calfat \\ University of Antwerp \\ Renato G. Flôres Jr. \\ Fundação Getulio Vargas/EPGE \\ Maria Florencia Granato
}

Universidad Nacional de Río Cuarto and Universidad Nacional de Villa María

\begin{abstract}
We evaluate the potential dynamic effects of MERCOSUR on the Argentinean economy. Two approaches, already used with other regional integration agreements, are applied for measuring medium and long-term effects. Special care has been taken in separating intra from extra zone effects. All estimations are carefully checked and have their magnitudes contrasted with other figures derived from different sources. Besides, complementary empirical assessments are done. The diverse empirical evidences found support the argument that Argentina experienced growth effects due to MERCOSUR.

- JEL Classifications: F15, F19, F14

- Key words: Economic integration, Dynamic effects, Country and industry studies of trade

\footnotetext{
*Corresponding address: Professor Germán Calfat, Institute of Development Policy and Management, University of Antwerp, RUCA, Universitair Centrum Antwerpen - Middelheimlaan 1, B-2020 Antwerp, Belgium, Tel: +32(0) 32180 620, Fax:+32 (0)3 2180 650, E-mail: german.calfat@ ua.ac.be Doctor Renato G. Flôres Jr., EPGE, Fundaçäo Getulio Vargas, Praia de Botafogo $19010^{\circ}$ andar 22253900 Rio de Janeiro RJ Brasil, Tel: +55-21-25595909, Fax: +55-21-25538822, E-mail: rflores@ fgv.br Professor Maria Florencia Granato: Universidad Nacional de Rio Cuarto, Ruta Nac. 36-km 601, CP X5804BYA, Rio Cuarto-Córdoba, Argentina, Tel: +54-358-4676200, Fax: +54-358-4680280, E-mail: fgranato@eco.unrc.edu.ar (O2003-Center for International Economics, Sejong Institution, All Rights Reserved.
} 


\section{Introduction}

Regional integration agreements (RIAs) may not only provoke static, but also dynamic effects on member countries. Theoretical and empirical results are however far from conclusive as to which channels may give rise to either medium-term or longterm growth. As a consequence, different and not necessarily compatible methodologies have been applied to measure the growth effects of actual RIAs.

In the case of MERCOSUR, empirical studies of its dynamic effects on member countries are certainly relevant, be it for evaluating the countries experiences within the bloc or for helping designing the next steps of the integration process. Notwithstanding, they are almost non-existent. Recently, using an inter-temporal general equilibrium model with eight regions, Diao and Somwaru (2000) performed a dynamic evaluation for Argentina and Brazil, later extended to the case of the FTAA (Free trade Area of the Americas) proposal, Diao and Somwaru (2001). At the side of such global, regional evaluations, individual country studies are dearly needed.

This paper tries to measure the potential dynamic effects of MERCOSUR on the Argentinean economy. Three approaches are applied: one used by Baldwin (1993) to evaluate the dynamic impacts of the European Union, another applied by Kehoe (1994) to approximate the growth effects of NAFTA on Mexico, and a further analysis of intra- and extra-zone trade, using Bhrülhart (1994)'s indexes. This allowed estimating both medium and long-run effects.

The results obtained are pervasively discussed and may suggest interesting theoretical points. In particular, our findings add evidence to the debate on SouthSouth integration versus North-South or North-North endeavours, which received formal grounding in Venables (1999 and 2000). All estimations are carefully checked and have their magnitudes contrasted with other figures derived from different sources. Besides, complementary empirical assessments are made with the intention of providing additional insights on the findings.

Of course, the present study is not free from methodological shortcomings. Approaches that attempt at specific quantitative explorations risk ignoring important general equilibrium interactions and may disregard relevant dynamic issues. It is also obviously difficult to disentangle from the perceived effects those due to the regional integration. Moreover, no discussion on the dynamic welfare impacts of MERCOSUR is made, a topic which must be considered in a complete evaluation of the agreement, and that is crucial nowadays given the social conditions of its members. With these caveats, the diverse empirical evidences found support the existence, in the 
Argentinean economy, of growth effects due to MERCOSUR.

The rest of the paper is organised as follows. Section 2 briefly summarises the theoretical and empirical literature on the relationship between RIAs and growth, making a critical analysis of the two methodologies adopted. In Section 3 a few stylised facts on the dynamic path of the Argentinean economy are discussed, as a motivation for the analyses performed. Results from the first two approaches are reported, analysed and contrasted in Section 4, while Section 5 exploits the marginal intra-industry trade concept and discusses additional evidences. The last Section concludes.

\section{Theoretical and Methodological Issues}

\section{A. Background Considerations}

Following Baldwin (1993), static effects are here defined as those that lead to more output from the same amount of inputs, where inputs include physical and human capital, as well as knowledge capital (technology). In perfectly competitive models, these static effects stem from changes in resource allocation and consumption possibilities, while in models with imperfect competition gains may result from increasing returns to scale-as firms realise internal scale economies, and from increased product and input variety. Dynamic effects are those that influence the accumulation of factors and, consequently, affect the growth in percapita income. As far as the rate of capital accumulation depends on the costs and benefits of investing in new human, physical and knowledge capital, for altering growth, RIAs must affect these very costs and benefits.

Though different in nature, both effects are significantly connected. Static efficiency gains are at the root of dynamic effects, their understanding being particularly important. ${ }^{1}$ One relationship between the two takes place through commerce of intermediate goods. The production of capital of either form may involve traded intermediates affected by trade barriers; hence the size of growth effects depends upon how important partners exports are in the capital-sectors cost function. The static and dynamic sides are also linked by inter-sectoral expenditure shifts. If traded sectors are relatively more capital-intensive than nontraded, RIAs, shifting expenditure to the traded capital-intensive sector, boost the derived demand for capital, increasing capital accumulation and growth. A third

\footnotetext{
'The following is a generalisation of Baldwin and Seghezza's (1998) ideas, which re-organise arguments present in previous papers as Baldwin (1989 and 1993) and Baldwin and Venables (1995).
} 
relationship relies on the fact that reciprocal liberalisation may produce a procompetitive effect, changing prices in the capital sector.

Dynamic or growth effects of RIAs are usually separated into medium-term and long-term effects. Neoclassical growth literature provides the framework for thinking about the former: liberalisation, through its static effects, may raise the return to capital, giving place to higher investment levels, an increase in the steady-state level of income -explained by the presence of diminishing returns to accumulation- and an associated medium-term rise in growth rates. Endogenous growth theory provides the framework to analyse the latter. Market integration may alter the rate of per-capita GDP growth, by affecting either the present value of investing in new capital or the cost of capital goods, as capital not facing diminishing returns on an economy-wide basis does not cease to be accumulated. ${ }^{2}$

Endogenous growth models, compared to neoclassical ones, allow consideration of a wider range of economic channels by which trade can affect growth. Grossman and Helpman (1991), drawing attention to the role of research and development activities, proposed that integration may lead to changes in income and growth through four principal channels. ${ }^{3}$ First, economic integration, even in the absence of trade flows, may enhance international dissemination of knowledge (international spillovers), allowing scientists in one country to learn more or faster from advances in other countries. Second, trade can eliminate duplication of innovations. Third, trade can expand effective market size for firms in each country - boosting profits, as $R \& D$ costs can be spread over a larger market -, and also increase the degree of competition facing domestic innovation. This pro-competitive effect may increase or decrease the incentive to innovate. While the former is the most common result predicted by endogenous growth models, the latter is also found in some, specially the Schumpeterian ones. Finally, because of changes in relative factor prices, trade can lead to changes in resource allocations, moving them to the R\&D sector. ${ }^{4}$

\footnotetext{
${ }^{2}$ Within almost all endogenous growth models, RIAs can also affect long-run growth through population rise, the scale effect.

${ }^{3}$ One important distinction among endogenous growth models is whether technological change results from the development of new blueprints through $R \& D$ or whether it results from a more efficient use of existing blueprints through learning by doing.

${ }^{4}$ See Rivera-Batiz and Romer (1991) for further theortical analysis on regional integration and endogenous growth.
} 
Most empirical studies and surveys on the dynamic effects of RIAs - as Baldwin and Seghezza (1996), USITC (1993), among others - agree on the lack of a unanimously accepted methodology for measuring such effects. The empirical studies, mainly carried on for the European case, can be placed into three different methodological groups. The first, which includes works like Baldwin (1989, 1992 and 1993), Baldwin and Seghezza (1996 and 1998), Diao et al. (2001) and Kehoe (1994), basically applies specific quantitative explorations. In order to capture the mechanisms through which RIAs may affect growth, they analyse indicators and their evolution (prima facie evidence) and make tentative calculations, of varying statistical sophistication, roughly derived from theoretical models. They qualify as approximations to the measurement of medium and long-run growth effects. A second set of studies estimates simple growth regressions using either cross-section data for a range of countries or time series data on individual countries. Examples are Levine and Renelt (1992), Lee (1992 and 1994), De Long and Summers (1991), Barro (1991), Coe and Helpman (1995), Backus et al. (1992), and, again, Baldwin and Seghezza (1996). A third group applies computable general equilibrium (CGE) models for estimating the growth effects of trade liberalisation. Though static CGE models are being increasingly used, there are few applications considering dynamic settings, and even less that incorporate endogenous growth mechanisms. Two examples of the latter are Rutherford and Tarr (1998) and Diao et al. (1999); while the already mentioned Diao and Somwaru $(2000,2001)$ try to answer questions similar to ours in a multiregional scale.

Each of the above categories presents well-known drawbacks. Within the first group, there is few or nothing to tie the dynamic effects specifically to the RIA enactment. Considering the econometric works, almost none derives the growth regression from a theoretical model. Moreover, most use strong prior beliefs to choose which variables are included in the equations, and incorporate investment as an exogenous variable, hence eliminating the possibility to capture investment creation. Dynamic CGE models are either poorly developed or too aggregate, and their effective use in the study of trade policy implications is only starting.

Attempts to measure MERCOSURs dynamic effects at a detailed country level seem not to have been made yet. Studies on static effects do exist, examples being Calfat and Flôres (1996), Flôres (1997) and Hinojosa et al. (1997). This paper is an effort to measure dynamic effects in the Argentinean economy. The different approaches here applied belong to the first group previously mentioned. In spite of their limitations, they were chosen for two main reasons. Firstly, the estimation of 
growth regressions would have required long time series data on Argentina, which are not available due to MERCOSURs short life; while building up a detailed dynamic CGE model for Argentina as a member-country -incorporating at least Brazil and Uruguay among the other regions-, though interesting and needed, should be preceded by works like this one. Secondly, applying Baldwins and Kehoes approaches ensures, as shown below, the consideration of both medium and long-term effects.

\section{B. The Methods Adopted}

Baldwin (1989) presents three ways to compute the growth effects of EC92. One of them -the aggregate GDP approach- permits estimating medium-run growth effects, and is used in this work. The other two, which compute long-run effects after modifying and calibrating Romer (1987)s and Krugman (1988)s approaches, respectively, seem even less robust than the former and are not applied here. The aggregate GDP methodology, derived from a neoclassical framework, consists in estimating the proportional rise in per-capita GDP $(\hat{Y})$ due to regional integration by the following equation:

$$
\hat{Y}=\left(\frac{\alpha}{1-\alpha}\right) \hat{\beta}+\hat{\beta}
$$

where $\hat{\beta}$ represents the static effects, and $\alpha$ is the capital-output elasticity. The second term captures the static efficiency effects, while the first one reflects the indirect increases in per-capita GDP due to the induced rise in the steady-state level of capital, or medium-run effects.

For estimating the growth effects of EC92 on European countries, Baldwin $(1989,1992)$ took the static gains from the Cecchini Report, and a range of estimates for the capital-output elasticity from different authors. Due to the fact that the size of $\alpha$ is an unsettled empirical question, most were estimations of the capital's share in income (or one minus labour's share in income). He concluded that the dynamic effect was considerable, and not dependent on the new growth theory, as it is present even within the Solow model.

Estimates from this approach are obviously rough, as its analytical framework has many drawbacks. It does not account for the fact that integration will not affect all sectors equally, and assumes, somewhat hopefully, that RIAs enhance physical capital accumulation. Actually, Baldwin assumes that the real return on forgone consumption $(r)$ is decreasing with the level of trade barriers $(\tau)$; however, in more general terms, by the Stolper-Samuelson theorem, $r$ may be either increasing or 
decreasing in $\tau$.

Kehoe (1994)'s methodology for studying long-run effects is based on Backus et al. (1992), who established statistical regularities across countries, linking intraindustry trade and inter-industry specialisation with growth. More specifically, he uses the changes in a specialisation index for exports and in the Grubel-Lloyd (intra-industry trade) index to infer whether, within a RIA, an increase in the manufacturing productivity growth rate may result. He assumes that, if a RIA leads to specialisation in final output and, henceforth, to industry output increases, learning-by-doing may result in continual productivity improvements leading to increased economic growth for the economy as a whole. Thus, the specialisation index tries to capture the relationship between trade, inter-industry specialisation, and economic growth. On the other hand, using the Grubel-Lloyd index to measure the extent to which a country trades in specialised intermediate inputs, Kehoe interprets that an increase of the index indicates that the country gains access to other countries experience, thereby raising its productivity growth.

The growth-accounting equation below, based on Backus et al. (1992) and derived after regressing the manufacturing productivity growth rate on the export specialisation and Grubel-Lloyd indexes (as well as other test variables: manufacturing output, per capita income and primary school enrolment) for a wide range of countries, is used to estimate the dynamic gains for Mexico from the NAFTA:

$$
g^{\prime}-g=0.309 \ln \left(E S^{\prime} / E S\right)+0.890 \ln \left(G L^{\prime} / G L\right)
$$

where and are the new and old productivity growth rates, andare the corresponding export specialisation indexes, and and the Grubel-Lloyd indexes.

Potential dynamic effects are thus obtained by making very crude assumptions regarding the integration impacts on the specialisation and Grubel-Lloyd indexes. Like other quantitative explorations, Kehoes approach fails to explicitly link trade policy with economic growth, and simply assumes that preferential trade liberalisation enhances growth, by increasing specialisation and intra-industry trade, when this is just a probable issue which should be proved.

\section{A Few Stylised Facts}

Table 1, showing the growth of trade within the region in such a short period as 1990-1993, provides a glimpse on the rapid success of MERCOSUR. It is interesting to notice that, in spite of more than doubling intra-regional exports and 
Table 1. MERCOSUR merchandise trade (million dollars), 1990-1993

\begin{tabular}{ccc}
\hline & (to/from) MERCOSUR & (to/from) Rest of the World \\
\hline MERCOSUR exports & 1990 & \\
MERCOSUR imports & 4,127 & 42,292 \\
& 4,241 & 25,054 \\
\hline MERCOSUR exports & 1993 & 44,059 \\
MERCOSUR imports & 10,026 & 39,121 \\
\hline
\end{tabular}

Source: World Trade Organisation (WTO).

imports, imports from the rest of the world also raised considerably, signalling though in a crude manner that the integration process cannot be considered a closed one.

As regards Argentina, Figure 1 shows that per-capita GDP picked up rapidly in 1990, just before MERCOSUR enactment and simultaneously with the countrys comprehensive programme of macroeconomic reforms (monetary and fiscal), tied to broad deregulation and privatisation plans. A higher rate of physical capital formation is behind this rapid growth; since 1990, after fourteen years of decline, the investment rate improved, achieving its past mid-1980s levels.

As a consequence of the positive investing behaviour, the stock of physical

Figure 1. Prima facie evidence for investment led-growth in Argentina.
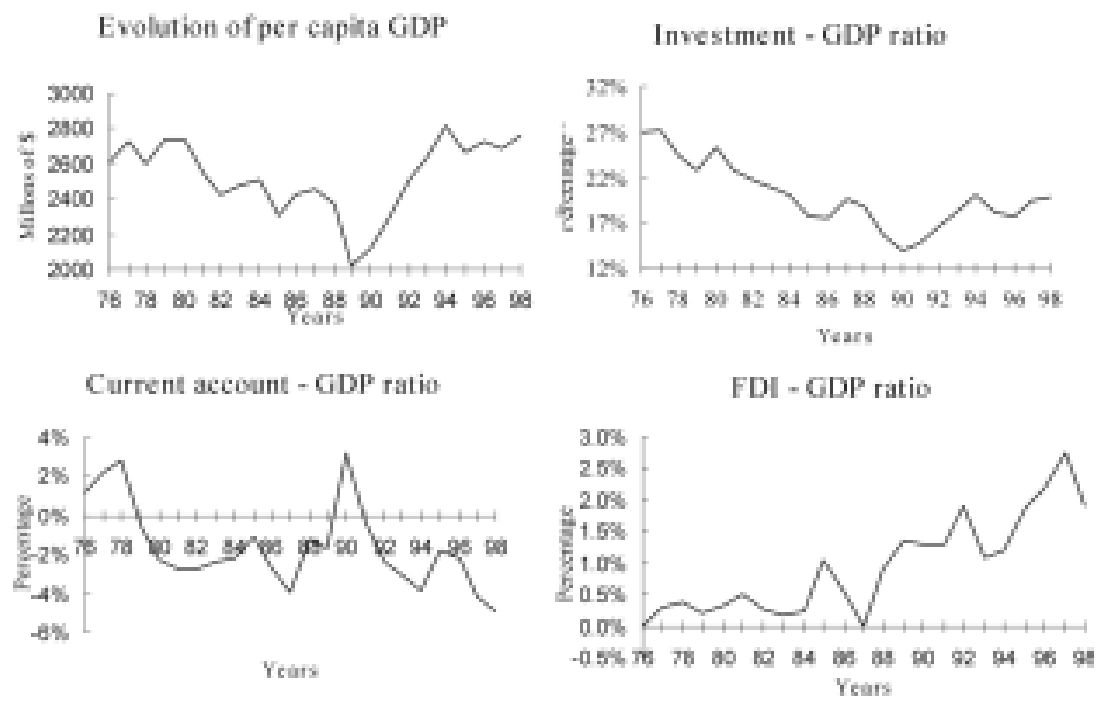
Figure 2. Importance of imported investment goods Percentage of total invetment goods.

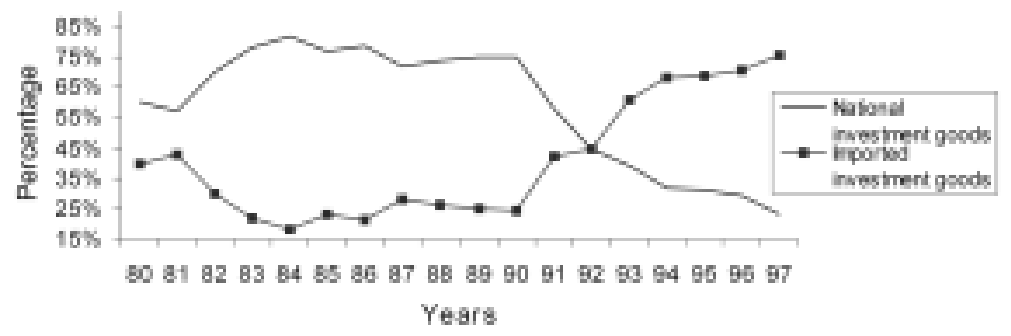

Source: Matinez, et al. (1998), based on Ministry of Economy.

capital has been continuously increasing, resulting, in 1996, 12\% greater than in 1991 and beyond its 1980s levels; something true for the three series of physical capital we observed (two from Martinez et al. (1998) and one built by Meloni (1998), on the basis of the first two). Studies like Martinez et al. (1998) and Bisang and Gomez (1999) indicate that the abrupt fall in the relative prices of capital goods - around 20\% between 1990 and 1996 - was a determinant factor for the accumulation process. This, together with the greater proportion of imported goods in the total of investment goods along the 1990s - over $62 \%$ average annual participation (see Figure 2), implies that trade liberalisation may have been boosting accumulation.

The right bottom panel in Figure 1 shows that the emergence of MERCOSUR was accompanied by foreign direct investment (FDI) inflows. The attractiveness of the country, enhanced since 1987, did rapidly rise with MERCOSUR between 1993 and 1997. In spite that important reforms of investment rules - which may explain at least some of the FDI evolution - had occurred before, this behaviour is certainly also due to the establishment, by MERCOSUR, of a new regime to promote and protect investment in the region of which the Colonia and Buenos Aires Protocols are examples.

The left bottom panel shows that the current account, after a short favourable period, has been in deficit since MERCOSUR enactment. This indicates a positive balance of the capital account and hence an entry of foreign capital into the country, which might have helped investment-led growth.

During the 1980s, imports maintained an almost constant level that contrasts with their positive trend in the 1990s. Explaining most of this evolution, as Figures 3 and 4 show, are intermediate and capital-good imports. ${ }^{5}$ 
Figure 3. Importance of capital-good and intermediate imports.

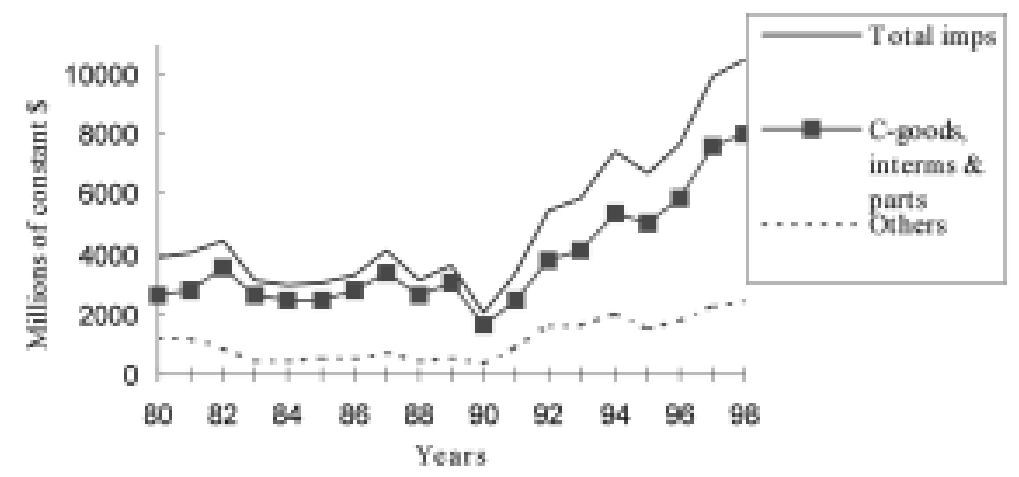

Source: Ministry of Economy (1994 and 1999).

Figure 4. Imports of capital-goods and intermediates.

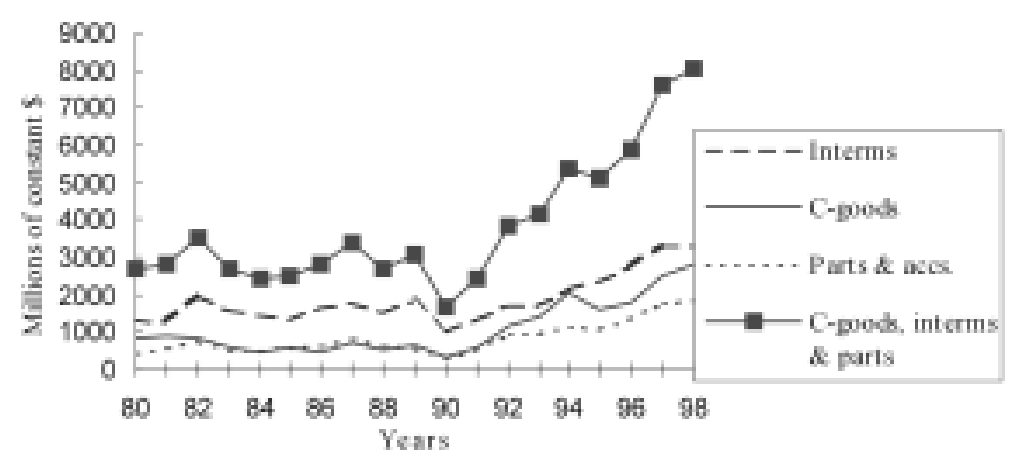

Source: Ministry of Economy (1994 and 1999).

\section{Measuring MERCOSUR Dynamic Effects}

\section{A. Medium-Term Effects}

Baldwins approach requires two values: an estimate of the static efficiency impact due to integration $(\hat{\beta})$ and an estimate of the capital-output elasticity $(\alpha)$.

Three different estimates of static gains were considered (see Table 2a). The first was obtained by Flôres (1997), and corresponds to a long-run solution within a static CGE model with imperfect competition and increasing returns to scale at firm level. Long-run solutions are defined in the paper as those resulting when

\footnotetext{
${ }^{5}$ Traded intermediates include imported parts and accessories, which are used for the production of capital goods.
} 
Table 2. Estimates for Baldwins approach

\begin{tabular}{lc}
\hline \multicolumn{1}{c}{ Author } & Estimate \\
\hline \multicolumn{1}{c}{ 2a. Static CGE efficiency impacts (as percentage of GDP) } \\
\hline Flôres (1997) & 1,80 \\
Hinojosa, et al. (1997) & 0,35 \\
Calfat and Flôres (1996) & 0,13 \\
\hline \multicolumn{1}{c}{ 2b. Capital-output elasticities $^{2}$} \\
\hline Meloni (1998) & 0,48 to 0,57 \\
& 0,40 to 0,51 \\
Grosz (1998) & 0,55 \\
& 0,52 to 0,58 \\
Ministry of Economy (1998) & 0,56 to 0,61 \\
De Gregorio (1998) & 0,4 \\
Traa (1996) & $0, \mathrm{a}$ \\
\hline
\end{tabular}

Notes: In the cases of Meloni and Grosz, the range of their multiple estimations (under different assumptions) was considered.

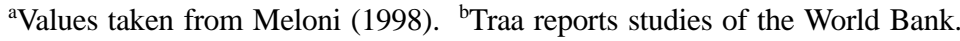

there is free entry-exit of firms and profits in traded sectors go to zero. They were computed for three different scenarios. We chose a value related to the solution for scenario "A", because it seems closer to reality. The second estimate is from Hinojosa et al. (1997), who used their NASAFTA model which incorporates, among other features, the possibility to capture the potential dynamic externalities as a result of liberalisation. The last comes from Calfat and Flôres (1996), who used a perfectly competitive set-up. It is worth mentioning that these estimates are not exactly comparable; however, using the three of them seems less arbitrary than choosing only one.

Capital-output elasticities, which are shown in Table $2 b$, were taken from different studies carried for Argentina. The estimations by Meloni (1998) come from three different output regressions: one with a Cobb-Douglas specification, with constant returns to scale and where production factors are quality-adjusted, and two others considering intensive forms of the production function, with quality-adjusted and non-quality-adjusted production factors, respectively. In the case of Grosz (1998), two output regressions were run for the traded sector, considering either a constant term for testing the presence of technological change or a dummy variable representing convertibility. The last three values of the table correspond to estimations of capitals share of income. ${ }^{6}$ 
Table 3. Estimated MERCOSUR medium-term and total effects (in \%)

\begin{tabular}{ccc}
\hline Static Impact & Medium-run effect & Total effect \\
\hline 1,80 & $1,20-3,34$ & $3,00-5,14$ \\
0,35 & $0,23-0,65$ & $0,58-1,00$ \\
0,13 & $0,09-0,24$ & $0,22-0,37$ \\
\hline
\end{tabular}

Given the above elasticities, a range of values going from 0,40 t 80,65 was considered for the estimation. The resultant Baldwin multiplier $\overline{1-\alpha}$, which gives the range of medium-run growth bonus, goes from 0,67 to 1,86 . The estimated total dynamic gains are presented in Table 3 . The range of values seems quite plausible and encompasses, for instance, Diao and Somwaru (2000)'s results of 1.36 and 2.10, from their two experiments with an inter-temporal CGE model.

Notes: From equation (1), the first term is the Medium-run effect and is Total effect. The values of Medium-run effect and Total effect on the right correspond to a capital-output elasticity of 0,65 , while those on the left correspond to a capital-output elasticity of 0,40 .

It can be concluded -as Baldwin did for EC92- that the dynamic effects may be considerably greater than the static ones. However, Argentina might not have benefited from the integration as much as certain European countries, basically due to the magnitude of static gains. The difference between the Argentinean and the top European cases may perhaps be explained by the kind of integration established through each programme: a starting, South-South integration with MERCOSUR and a deeper, North-North integration through EC92. The particular characteristics of, and qualitative dissimilarities between, these two types are fully discussed in World Bank (2000).

As a way of evaluating how meaningful the above results are, one should compare the estimated total effect with real data on per-capita output growth, as shown in Figure 1. Nevertheless, two problems appear. First, the growth rate in per-capita GDP may be explained by a number of different factors, being not

\footnotetext{
${ }^{6}$ See Meloni (1998), for a discussion on the alternative methods for estimating aggregate output functions as well as for understanding what he considers quality-adjusted production factors.

${ }^{7}$ For future research, it will be interesting to obtain MERCOSUR effects against a carefully designed antimonde, and then compare these estimates with those from Baldwins approach.
} 
possible to tie its actual movements and trend to an isolated issue such as trade policy. ${ }^{7}$ Second, we do not know the speed at which the values in Table 3 will come true. Notwithstanding, a tentative evaluation may be performed with the help of the neoclassical notion of speed of convergence.

Following Romer (1996) and Baldwin (1993), the dynamics around the steadystate is approximated by the following expression

$$
\frac{d Y / Y}{d t}=(n+\eta+\delta)(1-\alpha)\left(\ln Y^{*}-\ln Y_{t}\right)
$$

where $n$ is the rate of population growth, $\eta$ the exogenous rate of technological progress and $\delta$ is the depreciation rate. Under investment-led growth, considering yearly rates, per-capita GDP closes $\lambda=(n+\eta+\delta)(1-\alpha)$ percent of the gap between its current level $\left(Y_{t}\right)$ and the new steady-state level $\left(Y^{*}\right)$ each year.

We estimated the speed of convergence $\lambda$ for Argentina using:

i) Meloni (1998)'s value for total factor productivity growth rate of 4,07\% per annum, over 1990-1997, corresponding to the case of non quality-adjusted production factors (which is an internationally comparable method);

ii) an average yearly population growth of $1,33 \%$, corresponding to the very period, calculated using data in IMF (1999);

iii) a depreciation rate of $4 \%$ obtained from Reca (1998);

iv) the already applied range of values for the capital-output elasticity $(0,40$ to $0,65)$.

The resultant $\lambda$ is between 3,76 and $6,11 \%$, and implies that the convergence (or accumulation) process has a half-life of about 18 or 11 years, respectively. Taking now $Y^{*}$ to be the steady-state level implied by MERCOSURs total effects predicted in Table 3, and considering a five years horizon, the previous speeds imply that over 17 to $26 \%$ of the total effect should have been achieved within the first five years after MERCOSUR enactment. These values, for the different estimates obtained, appear in Table 4.

Note: The values on the left, for both columns, correspond to a capital-output

Table 4. Estimated percentage variations of GDP after five years of MERCOSUR

\begin{tabular}{cc}
\hline Total (long-run) effect & Effect after five years \\
\hline $3,00-4,50$ & $0,51-1,18$ \\
$0,58-0,88$ & $0,10-0,23$ \\
$0,22-0,33$ & $0,04-0,09$ \\
\hline
\end{tabular}


elasticity of 0,40 , and those on the right to a capital-output elasticity of 0,65 . The left column reproduces the different long-run dynamic effects found in Table 3.

The actual proportional change of Argentinean per-capita GDP between 1991 and 1996 was of 18,45\%, and of 4,85\% between 1993 and 1998, IMF (1999). Though the second period covers years during which it is safer to ensure that at least some static effects of MERCOSUR had already taken place, both largely support the results obtained from Baldwins methodology, if the static imperfectcompetition gains are used.

\section{B. Long-Term Effects}

The data for estimating the long-run effects correspond to manufacturing sectors positions 500 to 899 of the Standard International Trade Classification (SITC), revision 3, at the three-digit level - i.e. same level as Kehoes - and were obtained from the DATA INTAL database for the period 1986-1996. Values were converted from US dollars to Argentinean pesos, and deflated by exchange rates and GDP deflators published in IMF (1999). The period considered imposes an important restriction on the analysis, given that MERCOSURs Customs Union was not fully established until 1995. However, less ambitious forms of regional integration had been pursued by MERCOSUR countries, through bilateral agreements, since the mid-1980s, so that much of intra-regional trade had been already liberalised by 1994 (see Blomström and Kokko (1997), for instance). Though it is somewhat early to detect even the static effects on foreign investment, tentative conclusions may be drawn from the regions experience since the mideighties.

A few modifications were introduced in Kehoes methodology. One was to ignore the export specialisation index, due to the impossibility to find the required manufacturing output data. This means that one of the channels for endogenous technical change, specialisation in final production and the subsequent learning-by-doing process was not analysed. ${ }^{8}$ Another change, now rather an improvement, was to calculate (and not, assume) the new values of the Grubel-Lloyd index $\left(G L^{\prime}\right)$, by dividing the data into pre- and post-MERCOSUR periods. The estimate of the change in the growth rate of manufacturing productivity $\left(g^{\prime}-g\right)$ thus results, at least partly, from the MERCOSUR enactment, reducing the lack of empirically-proved linkages between trade and

\footnotetext{
${ }^{8}$ For accurately measuring the export specialisation index $(E S)$ it would be necessary to have Argentinean output data classified by the SITC (revision 3), which was, to the extent of our knowledge, unavailable.
} 
Table 5. Estimated percentage change in manufacturing productivity growth rate

\begin{tabular}{lcccc}
\hline \multicolumn{1}{c}{ Compared periods } & GL & GL' & Log GL'/GL & $\left(\mathrm{g}^{\prime}-\mathrm{g}\right)$ \\
\hline \multicolumn{5}{c}{ 5a. Total change } \\
\hline i) 1986 vs. 1996 & 0,34 & 0,41 & 0,187 & 0,166 \\
ii) pre vs. Post & 0,39 & 0,40 & 0,025 & 0,023 \\
\hline \multicolumn{5}{c}{ 5b. Intra-zone change } \\
\hline i) 1986 vs. 1996 & 0,44 & 0,63 & 0,319 \\
ii) pre vs post & 0,39 & 0,66 & 0,359 \\
\hline \multicolumn{5}{c}{ 5c. Extra-zone change } \\
\hline i) 1986 vs 1996 & 0,20 & 0,22 & 0,518 \\
ii) pre vs post & 0,17 & 0,27 & 0,106 \\
\hline
\end{tabular}

growth in the approach.

Estimation was carried out in two different ways, according to how the GrubelLloyd indexes were obtained: i) for specific years: one before, 1986, and another after MERCOSUR formation, 1996, or ii) as averages for the pre- and postMERCOSUR periods. In the second case, periods correspond to 1986-1988 and 1994-1996. This is because 1989 and 1990 were recessive and hyper-inflationary, not normal, years; while the selection of 1994-1996 aimed at capturing some of the actual integration dynamics. The reason for using these two options, apart from Kehoe also doing the same, was that, ex-ante, both seemed reasonable.

Table 5a shows the estimated changes in the average yearly manufacturing productivity growth rate due to MERCOSURs likely impacts on intra-industry trade flows. Results are very sensitive to the periods used, and show that integration, through greater trade in specialised inputs, increased manufacturing productivity growth rate by an additional range of 0,02 to $0,17 \%$ per year. After thirty years, the level of output per worker in Argentina will be 0,60 to 5,23\% higher than otherwise.

Computing again the changes for Mexico, when only the assumed change in the Grubel-Lloyd index is considered, Mexican manufacturing productivity growth rate would have increased by an additional $0,242 \%$ per year, so that, after thirty years, the output per worker would be $7,52 \%$ higher than without NAFTA. Thus, the potential effects of MERCOSUR look somewhat smaller. Perhaps, as Baldwin and Seghezza (1998) proposed, R\&D-based links, which give rise to tradeinduced knowledge-led growth, may, to some extent, be disconnected from the realities of the integration among less developed countries, in contrast to the situation in which at least one member is a highly developed nation. Such North- 
South integrations, as the North-North ones already mentioned in the previous subsection, also usually fare better than the South-South ones.

To evaluate the accuracy of the results, we tried to compare them with the actual evolution of total factor productivity (TFP). However, the most suitable estimations of TFP annual growth rate found for pre- and post-MERCOSUR periods, $-1,83$ and 4,07\% between, respectively, 1980-1989 and 1990-1997, Meloni (1998), cannot be directly compared with the $\left(g^{\prime}-g\right)$ estimates, as they correspond to crucially different periods, both in terms of trade policy and macroeconomic setting.

A further interesting issue is then to compare the change in the manufacturing productivity growth rate that would have been caused by Argentinean intraMERCOSUR trade on one side, and extra-MERCOSUR trade on the other. This is likely to reveal the main effect of MERCOSUR until 1996, which may have acted through intra-zone rather than extra-zone trade liberalisation. ${ }^{9}$ Besides, it can help to isolate an effect exclusively explained by MERCOSUR formation, and not by the Argentinean unilateral liberalisation, which had already started in 1988. For accomplishing this, $\left(g^{\prime}-g\right)$ was re-estimated twice: one using the change in the Grubel-Lloyd index for intra-zone trade, and another employing the change in extra-zone intra-industry trade. The results, for the same periods taken into account before, are presented in Table $5 \mathrm{~b}$ and $\mathrm{c}$. The change in trade flows among Argentina, Brazil, Paraguay and Uruguay explains a greater increase in the manufacturing productivity growth rate than the one due to the change in Argentinean extra-zone trade. Nevertheless, especially in the (more robust) pre and post-MERCOSUR case, the difference seems not so significant, either because the dynamic impacts had not yet taken place or perhaps due to the importance of the effects of Argentinean unilateral trade liberalisation.

\section{Additional Evidence on the Dynamic Effects}

The empirical evidences found in the previous section suggest that, either from a neoclassical or from an endogenous growth perspective, regional integration might have benefited the Argentinean economy by temporarily or permanently raising its growth rates. The following analyses give an extra support to the

\footnotetext{
${ }^{9}$ It is referred to extra-zone liberalisation because the average common external tariff (CET) of MERCOSUR has resulted lower than the previous Argentinean average external tariff (see Izam (1998)).
} 
argument.

\section{A. Re-Measuring the Change in Trade Flows of Specialised-Inputs}

Kehoes methodology, by considering the change in the Grubel-Lloyd (GL) index, may not in fact address the change in intra-industry trade. Brülhart (1994) pointed out that an observed increase in intra-industry trade levels -e. g. in the GL index- between two periods could hide an uneven change in trade, concomitant with inter- rather than intra-industry specialisation. Thus, for measuring the extent to which a country becomes more or less open to trade in highly specialised inputs than in the past, a dynamic analysis of intra-industry trade is needed. In this direction, Brülhart proposed the $A$ or marginal intra-industry trade (MIIT) index, which calculates the degree of intra-industry trade in total new trade by evaluating the marginal change in trade flows. The $A$ index is defined as:

$$
A=1-\frac{\left|\Delta X_{t, n}-\Delta M_{t, n}\right|}{\left|\Delta X_{t, n}\right|+\left|\Delta M_{t, n}\right|}
$$

where $\Delta X_{t, n}=X_{t}-X_{t-n}$ and $\Delta M_{t, n}=M_{t}-M_{t-n}$ are, respectively, the differences between the current values of exports and imports, and their values $t-n$ periods before. Like the GL measure, $A$ varies between 0 and 1: 0 indicates marginal trade in the particular industry to be completely of inter-industry type, and 1 to be entirely of the intra-industry type, Brülhart (1994, page 605).

The $A$ index was calculated for each three-digit manufacturing sector, using the same trade data as before, and considering the same two time options. They were then summed across industries, by scaling for gross trade, generating a global measure of MIIT. Three different gross trade-scaling weights were considered:

Table 6. Marginal intra-industry trade indexes, 1986 to 1996

\begin{tabular}{lccc}
\hline \multicolumn{1}{c}{ Compared periods } & $A$ (initial) & $A$ (final) & $A$ (av. init.-final) \\
\hline \multicolumn{4}{c}{ 6a. Global trade } \\
\hline i) 1986 vs. 1996 & 0,31 & 0,37 & 0,35 \\
ii) pre vs. Post & 0,30 & 0,33 & 0,32 \\
\hline \multicolumn{4}{c}{ 6b. Intra-zone trade } \\
\hline i) 1986 vs. 1996 & 0,42 & 0,60 & 0,57 \\
ii) pre vs. Post & 0,34 & 0,61 & 0,55 \\
\hline & 6 c. Extra-zone trade \\
\hline i) 1986 vs. 1996 & 0,19 & 0,18 & 0,19 \\
ii) pre vs. Post & 0,04 & 0,22 & 0,04 \\
\hline
\end{tabular}


initial, final and the average initial-final gross trade; the MIIT index for this last one seeming the most directly comparable measure with the change in the GrubelLloyd indexes already calculated.

Table 6a presents the six global MIIT indexes obtained. All results indicate an increase in the trade in specialised inputs, as was also the intention behind the use of the change in the Grubel-Lloyd indexes in Kehoes methodology. However, compared to the "changes" displayed in the third column of Table 5, the MIIT indexes suggest a higher intra-industry specialisation than the previous analysis, thus providing stronger support to potential knowledge-driven growth effects.

Note: All column values were obtained after summing across industries, scaling for initial, final and the average initial-final gross trade, respectively.

The MIIT indexes were also calculated for the intra- and extra-MERCOSUR trade, with the objective of isolating effects that could be exclusively explained by the integration. Table $6 \mathrm{~b}$ and $\mathrm{c}$ shows that the long-run effects due to trade linkages among members appear to be, as a likely implication of the results, more important than those explained by the evolution of extra-zone trade.

Finally, following Brülhart (1994), we compared the evolution of (marginal) intra-industry trade both before and after MERCOSUR formation, instead of looking at its change between two separated periods. Hence, taking 1991 as a breaking point, two global $A$ indexes (using the "average initial-final" weights) were calculated for each trade flow -intra- or extra-zone, and total trade-, one measuring the change between 1986 and 1990 and the other that between 1992 and 1996.

All intra-industry trade flows in Table 7 have changed their evolution since 1991, becoming much more dynamic after the formation of the bloc. Though the greatest percentage change of MIIT has occurred for extra-zone trade $(600 \%)$, the highest index, 0,468, has shown up for the intra flows and, indeed, within the post-MERCOSUR period. This also supports the idea of MERCOSUR giving

Table 7. A comparison between MIIT indexes for intra- and extra-MERCOSUR trade

\begin{tabular}{cccc}
\hline & Intra-zone trade & Extra-zone trade & Total trade \\
\hline $1986-1990$ & 0,132 & 0,022 & 0,099 \\
$1992-1996$ & 0,468 & 0,154 & 0,375 \\
\hline
\end{tabular}


place to growth effects.

\section{B. Prima Facie Evidence}

We analyse here prima facie evidence for investment-led growth in Argentina. Following Baldwin and Seghezza (1998), we search whether, in parallel with the evolution of MERCOSUR: i) the ratio of aggregate investment to GDP has increased, ii) net foreign direct investment (FDI) improved, and iii) the current account deteriorated. ${ }^{10}$ As an attempt to deepen the study, beyond investment-led growth, we also address skill- and technology-led growth, by analysing investment in physical capital, investigating the role played by FDI in the growth process and reviewing data on the evolution and composition of the current account.

The evidences in Figures 1 and 2, discussed in Section 3, are in favour of a capital accumulation process helped by MERCOSUR. Nevertheless, as both Martinez et al. (1998) and Bisang and Gomez (1999) suggest, the entire programme of economic reforms in Argentina may be explaining the movement in the relative prices of capital-goods. Anyhow, the rising importance of imported investment goods in total investment goods supports the possibility of knowledgeled growth in Argentina, a point further analysed below. Also, in spite of a clear indication of foreign capital entry into the country, helping investment-led growth, only a more disaggregate analysis of the current account can give additional information on the potential growth effects. Due to this, some basic analyses of imports must be performed.

Figures 3 and 4 showed that intermediate and capital-good imports explained most of the imports evolution in the 1990s. ${ }^{11}$ In the case of intermediates, their increased trade could have boosted investment-led growth as far as they are potentially used by the capital sector; this apart from the knowledge-driven growth implications of increased trade in specialised intermediate inputs investigated in section 4.2. On the other hand, entry of foreign capital goods, generally high-tech products, might have acted as a conduit for the international diffusion of technology, and then as a propagator of knowledge-led growth.

As a check to this type of analysis, it is interesting to look at changes in the

\footnotetext{
${ }^{10} \mathrm{~A}$ fourth condition, the increase in stock market prices, was not used, as the Argentinean stock market does not comprise a representative sample of firms.

${ }^{11}$ Traded intermediates include imported parts and accessories, which are used for the production of capital goods.
} 
Table 8. Importance of human capital- and technology-intensive manufacturing imports in Argentina

\begin{tabular}{llcccccc}
\hline & \multicolumn{1}{c}{ Origin } & 1986 & 1988 & 1990 & 1992 & 1994 & 1996 \\
\hline H. cap. and tech. & Intra-zone trade & 14,0 & 22,2 & 19,0 & 23,0 & 19,8 & 21,5 \\
Intensive goods & Extra-zone trade & 86,0 & 77,8 & 81,0 & 77,0 & 80,2 & 78,5 \\
Total & Intra-zone trade & 12,7 & 20,3 & 17,1 & 20,0 & 17,5 & 18,5 \\
Manufactures & Extra-zone trade & 77,9 & 71,1 & 73,1 & 66,8 & 68,7 & 67,8 \\
\hline
\end{tabular}

Source: DATA INTAL (at 3-digit level SITC, rev. 3). Values were converted from US dollars to Argentinean pesos and deflated using IMF (1999) exchange rates and GDP deflators. Classification of manufacturing imports was according to Intal (1997).

origin of imports of technology- and human capital-intensive manufactures. Between 1986 and 1996, Argentinean imports of these goods were never less than $86 \%$ of total manufacturing imports, and they oscillated between 80,2 and $91,4 \%$ of its total manufacturing imports from MERCOSUR.

Table 8 shows that the average annual proportion of intra-zone imports in the total was, after MERCOSUR enactment, 3,4 points higher than before. Moreover, while intra-zone imports changed from $16,3 \%$ to $18,4 \%$ of all manufacturing imports - as an average annual proportion before and after MERCOSUR formation, respectively -, extra-zone imports fell from $82,2 \%$ to $68,2 \%$ of that total (i.e. the sum of human capital- and technology-intensive manufactures, natural resources-intensive products and non-labour-intensive manufactures). Therefore, although intra-zone imports of human capital- and technologyintensive manufactures have never surpassed $23 \%$ of the total trade in these goods, MERCOSUR may be explaining most of their rise during the period and, as a consequence, at least some skill- and knowledge-led growth in Argentina during the last decade.

Summing up, there is favourable prima facie evidence on MERCOSUR-led growth for Argentina.

\section{Concluding Remarks}

We conclude that both medium and long-run growth effects took place in Argentina, though they seem to be smaller than those for EC92, and perhaps for Mexico in the NAFTA. In both cases, the singular MERCOSUR nature of SouthSouth integration may mainly explain the differences. EC92 is a deeper integration between developed nations, and Mexicos possibly larger benefits may 
take place because the other NAFTA members, technologically-advanced economies, are actually able to induce knowledge-led growth. Though MERCOSURs other partners are not much more advanced than Argentina, the results show that even South-South RIAs may make a strict economic sense, if more modest.

The complementary analysis of MIIT indexes also supports the existence of growth effects, by showing that intra-industry specialisation, central to endogenous growth models, has risen and that its change has been indeed significant for Argentinean intra-MERCOSUR trade.

The analysis of prima facie evidence is coherent with MERCOSUR-induced investment-led growth. Besides, there seems to be evidence of knowledge dissemination through trade flows and FDI, which would imply induced knowledge-led growth in Argentina. This analysis has also shown that the macroeconomic situation of the country and the importance of its early 1990s reforms clearly contributed to the evolution of GDP, investment, the current account and the FDI flows. It is obviously difficult to disentangle these effects from those due to the regional integration.

The present study naturally suffers from other methodological shortcomings, and further research on the dynamic implications of MERCOSUR is definitely needed. The search for methodologies that may overcome some of the limitations addressed in this paper, like Feenstra et al. (1999)'s sectoral or "micro-based tests" of the determinants of growth, and the design and construction of more dynamic CGE models, in a country basis and incorporating endogenous growth mechanisms, are ways that should be pursued.

Received June 2001, Accepted 27 January 2003

\section{References}

Backus, D. K., P. Kehoe and T. J. Kehoe (1992) In Search of Scale Effects in Trade and Growth. Journal of Economic Theory 58, 377-409.

Baldwin, R. (1989) The growth effects of 1992. Economic Policy. October, 247-281.

Baldwin, R. (1992) Measurable Dynamic Gains from Trade. Journal of Political Economy 100(1), 162-174.

Baldwin, R. (1993) On the Measurement of Dynamic Effects of Integration. Empirica 20, 129-145.

Baldwin, R. and E. Seghezza (1996) Growth and European Integration: Towards an 
Empirical Assessment. CEPR Discussion Paper, No.1393.

Baldwin, R. and E. Seghezza (1998) Regional Integration and Growth in Developing Nations. Journal of Economic Integration 13(3), 367-399.

Baldwin, R. and A. Venables (1995) Regional Economic Integration. Handbook of International Economics, vol. III. (G. Grossman and K. Rogoff Eds.), 1597-1644.

Barro, R. (1991) Economic Growth in a Cross-section of Countries. Quarterly Journal of Economics, CVI, 2, 407-443.

Bisang, R. and G. Gomez (1999) Las Inversiones en la Industria Argentina en la Década de los Años Noventa. CEPAL Documento de Trabajo LC/BUE/R. 239, Buenos Aires. Blomström, M. and A. Kokko (1997) Regional Integration and Foreign Direct Investment: A Conceptual Framework and Three Cases. Policy Research Working Paper 1750. The World Bank.

Borensztein, E., J. De Gregorio and J-W. Lee (1998) How does foreign direct investment affect economic growth? Journal of International Economics 45, 115-135.

Brülhart, M. (1994) Marginal Intra-Industry Trade: Measurement and Relevance for the Pattern of Industrial Adjustment. Weltwirtschaftliches Archiv 130(3), 600-613.

Calfat, G. and R. G. Flôres Jr. (1996) Latin American Option for the European Union. Integration and Specialization, Coimbra, 311-329.

Coe, D.T. and E. Helpman (1995) International R\&D Spillovers. European Economic Review. 39, 5, 859-887.

Curi, G. N. (1999) Areas Comerciales Preferenciales: Evaluación Comercial Del Mercosur. Online. Internet. www.aaep.org.ar/espa/anales/98-99.htm\#rosario.

Diao, X., T. Roe and E. Yeldan. (1999) Strategic policies and growth: an applied model of R \& D-driven endogenous growth. Journal of Development Economics 60, 343-380. Diao, X., T. Roe and A. Somwaru. (2001) What is the cause of growth in regional trade: trade liberalization or RTAs? The case of agriculture. The World Economy 24(1), 51-79.

Diao, X. and A. Somwaru. (2000) An enquiry on general equilibrium effects of MERCOSUR an intertemporal world model. Journal of Policy Modeling 22(5), $557-$ 588.

Diao, X. and A. Somwaru. (2001) A dynamic evaluation of the effects of a Free Trade Area of the Americas an intertemporal global general equilibrium model. Journal of Regional Integration 16(1), 21-47.

De Long and L. Summers (1991) Equipment Investment and Economic Growth. Quarterly Journal of Economics. 445-502.

Feenstra, R., Dorsati M., Tzu-Han Y. and Chi-Yuang L. (1999) Testing endogenous growth in South Korea and Taiwan. Journal of Development Economics 60, 317-341.

Flôres, R. G. Jr. (1997) The gains from MERCOSUL: A general equilibrium, imperfect competition evaluation. Journal of Policy Modeling 19(1), 1-18.

Grossman, G. and E. Helpman (1991) Innovation and Growth in the Global Economy. Cambridge, Mass. MIT Press.

Grosz, F. A. (1998) Un estudio del crecimiento en el sector transable de la economía argentina: 1970-1997. Online. Internet. www.aaep.org.ar/espa/anales/98-99.htm\#rosario 
Hinojosa, R., Lewis and S. Robinson (1997) Simon Bolivar Rides Again? Pathaways Toward Integration between NAFTA, MERCOSUR and the Greater Andean Region. Integration and Trade January-April (1), 95-122.

INTAL (1997) Informe MERCOSUR. Año 2, No 3. Julio-Diciembre. Buenos Aires. International Monetary Fund (1999) International Financial Statistics Yearbook. Vol. LII. Washington, D.C.

Izam, M (1998) Estructura y nivel del arancel externo del Mercado Comun del Sur (MERCOSUR). CEPAL Documento de Trabajo LC/R. 1800, Santiago de Chile.

Kehoe, T. J. (1994) Assessing the Economic Impact of North American Free Trade. In The NAFTA Debate. Grappling with Unconventional Trade Issues (M. Delal Bayer and Sidney Weintraub Eds.), pages 3-33. Lynne Rienner Publishers, London.

Lee, J-W (1993) International Trade, Distortions and Long Run Growth. IMF Staff Papers, 40, 2, 299-328.

Lee J-W (1994) Capital Goods Imports and Long Run Growth. NBER Working Paper. $\mathrm{N}^{\circ}$ 4725.

Levine R. and D. Renelt (1992) A Sensitivity Analysis of Cross-country Growth Regressions. American Economic Review. 82, 4, 942-963.

Martinez, R., P. Lavarello and D. Heymann (1998) Inversiones en la Argentina: Aspectos macroeconomicos y analisis de los equipos importados. Online. Internet. www.aaep.org.ar/espa/anales/98-99.htm\#rosario

Meloni, O. (1998) Algunas Estimaciones del Producto Potencial de Argentina. Online. Internet. www.aaep.org.ar/espa/anales/98-99.htm\#rosario

Ministry of Economy (1999) La Inversion Extranjera Directa en Argentina 1992-1998.

Direccion Nacional de Cuentas Internacionales. Online. Internet. www.mecon.ar/ cuentas/internacionales/default1.htm

Ministry of Economy (1999) Informe Economico. Año 8, Numero 30, Buenos Aires.

Ministry of Economy (1994) Informe Economico. Año 2, Numero 8, Buenos Aires.

Oliveras, J. and I. Terra (1997) Marginal Intra-Industry Trade Index: The Period and Aggregation Choice. Weltwirtschaftliches Archiv 133(1), 170-178.

Reca, A. (1998) Acumulacion de Capital en un Modelo de Equilibrio General: Una Aplicación para Argentina. Online. Internet. www.aaep.org.ar/espa/anales/9899.htm\#rosario

Rivera-Batiz, L. and P. Romer (1991) Economic integration and endogenous growth. Quarterly Journal of Economics. Vol. 106, 531-555.

Romer, D. (1996) Advanced Macroeconomics. McGraw-Hill.

Rutherford F. and Tarr D. (1998) Trade Liberalization and Endogenous Growth in a Small Open Economy. Policy Research Paper, $\mathrm{n}^{\circ}$ 1970, World Bank.

United States International Trade Commission (1993) The Dynamic Effects of Trade Liberalization: A Survey. USITC Publication 2608, Investigation No. 332-324. Washington.

Venables, A.J. (1999) Regional Integration Agreements: a force for convergence or divergence? Proceedings of World Bank ABCDE Conference. Policy Research 
Working Paper Series n ${ }^{\circ} 2260$. World Bank, WashingtonD.C.

Venables, A. J. (2000) Winners and Losers from Regional Integration Agreements. CEPR Discussion Paper, No. 2528.

Wacziarg, R. (1998) Measuring the Dynamic Gains From Trade. Policy Research Working Paper 2001. The World Bank.

World Bank (2000) Trade Blocs. Policy Research Report. Washington DC. 